\title{
Physiological Responses of Boxing Exercises and Effect on Elite Boxers
}

\author{
Merve Uca', Fatih Kilinç² \\ ${ }^{1}$ Department of Sport Sciences, İstanbul Aydin University, \\ Istanbul, Turkey \\ ${ }^{2}$ Department of Sports Sciences, Akdeniz University, Antalya, \\ Turkey
}

Study Area: Istambul, Turkey

Coordinates: $41^{\circ} \mathrm{oo}^{\prime} 49$ ? N 28 $57^{\prime} 18$ ? E

Key words: Boxing Match, Blood Pressure, Body

Temperature, Pulse Rate

\section{Introduction:}

Boxing is generally a combat sport in which two people of the same weight get points under the supervision of the referee by punching each other in three rounds of three minutes. Significant changes have been made in the technical and competition rules in boxing. Among these changes, especially the increase in the duration and the number of rounds, causes increasing changes in the physiological structure of the boxers. On the other hand, despite the short length of the boxing match (3 rounds $\mathrm{x} 3$ minutes), they focused on the necessity of the boxers to have the necessary equipment to make an intense effort in the ring (El-Ashker, 2011). However, most of the experts in the field of combat sports have focused on studies on physiological changes associated with combat effort (Beneke et al., 2004; Toskovic et al., 2002; Kravitz et al., 2003; Ghosh, 2010; Chatterjee et al., 2006). In this study, it is focused on determining the differences or similarities in the blood pressure, body temperature, and heartbeat numbers among the physiological changes in the training and competition conditions of elite-level boxers. In this context, successful training adaptations to increase boxing competition efficiency without decreasing energy production caused positive physiological changes in athletes and increased performance levels.

The energy obtained from aerobic and anaerobic metabolism depends on the intensity and length of the activity (Kraemer et al., 2011). Short breaks in boxing expressed by high-intensity movements throughout the round are not enough for a full recovery. In addition, these

\section{Abstract}

The study was carried out on 28 elite boxers from Sakarya Boxing Club of the volunteer participants of our study. The tension, the body temperature and the pulse of participants were checked at the beginning of the study, during the study and after the study. Before training and match in systolic and diastolic tension values, after training and match in sytolic tension values observed significant differences, but in the other tension, values were not observed any differences. Before training and match in body temperature values were observed differences, in the other values were not observed any significant differences. Before training and match were not observed significant differences in the pulse values, but after training and match, we observed differences in the pulsevalues.

intensive movements cause high lactic acid production and high blood lactate (Khanna \& Manna, 2006). Therefore, during the boxing competitions, heart increases, and high blood lactate concentrations put a heavy burden on boxers (Ghosh et al., 1995). Simultaneously, physiologists and athletes need to be more conscious of the biochemical changes that can be caused by prolonged exercise (Warburton et al., 2002). As a result, the best method to evaluate training programs and prevent overtraining is to examine selected biochemical markers (Urhausen \& Kindermann, 2002; Gleeson, 2002; Umeda et al., 2008). Therefore, coaches or trainers should be familiar with physiological perspectives related to education.

There are few studies in the literature regarding the physiological demands of boxing (Khanna \& Manna, 2006). Studies have been conducted on heart rate, maximum oxygen uptake ( $\left.\mathrm{VO}_{2} \mathrm{Max}\right)$, blood lactate $(\mathrm{BL})$, which are the physiological requirements of boxing (Kravitz et al., 2003; Ghosh, 2010; Ghosh et al., 1991). The aim of this study is to determine the differences or similarities between the physiological changes in the training and competition conditions of the elite level boxers in blood pressure, body temperature, and heart rate.

Fever is one of the most common complaints of childhood. It is a clinical condition that is misinterpreted by families and often improperly treated. Most of the families describe high fever as a disease rather than symptoms. The approach to fever differs in different ethnic origins and beliefs. When the body temperature is measured between $30-37^{\circ} \mathrm{C}$, one-fifth of the parents evaluated this situation as

*Corresponding Author: merveuca@aydin.edu.tr 
fever and emphasized that medication should be given immediately (Saz, 2009). Therefore, it reveals the necessity for families to have information about why the fever is caused, how it should be measured and evaluated, and what treatment process they should follow.

Fever is considered to be a rise in body temperature. Body temperature is $37^{\circ} \mathrm{C}$ on average for humans. Body temperature values above $38^{\circ} \mathrm{C}$ rectally, $37.8^{\circ} \mathrm{C}$ in the ear, $37.2^{\circ} \mathrm{C}$ in the armpit are considered as fever. Fever occurs as a result of some biochemical reactions. Heat is released due to blood flow, heart and muscle movements, bowel movements, and the work of body organs. Keeping the body temperature within normal values is provided with blood flow and sweat glands in the skin. Substances secreted by bacteria or viruses stimulate the body and cause an increase in substances called endogenous pyrogen. These pyrogens also act on the hypothalamus in the brain, raising the preset thermostat temperature. During the rise of body temperature, symptoms such as shivering and a feeling of cooling in the hands and feet due to temporary narrowing of the peripheral vessels occur. Metabolic rate increases by $10-12 \%$ for every $1{ }^{\circ} \mathrm{C}$ rise above $37^{\circ} \mathrm{C}$. With it, the need for fluid and calories increases, heartbeat accelerates. All this puts an additional load on the heart and respiratory system. The body temperature, which is kept constant against the changes in environmental temperature, is between 36.5-37 ${ }^{\circ} \mathrm{C}$. It was observed that the body temperature in children was lowest in the early hours of the morning, and the temperature was highest between 16.00-18.oo PM. It is known that the daily changes in body temperature have a cyclical structure that occurs during the day. Normally, daily fluctuations are up to $0.6^{\circ} \mathrm{C}$. The hypothalamus is primarily responsible for the occurrence of fever in response to exogenous, endogenous, and pyrogens. The armpit area is a frequently preferred area for measuring body temperature in children. Normally, the temperature measured orally is $0.5^{\circ} \mathrm{C}$ higher than the armpit and the breech temperature is $0.8^{\circ} \mathrm{C}$ higher (Alp et al., 2012).

The heart is in the chest cavity, between the lungs, and under the protection of the breastbone and ribs. The lower part of the heart is against the diaphragm. The heart, an extremely powerful muscle, is partly the size of each person's own fist. An adult's heart weighs on average 300 grams. It is among the duties of the heart to pump blood with enough pressure to reach the whole part of the body and to ensure continuous circulation. The amount of blood the heart will pump in a day is approximately 4 thousand 730 liters (http://www.sporakademisi.com). The heart, as the engine of the body, starts working in the womb and continues to work until death. With the arteries and veins, the heart sends foodstuffs and oxygen to the whole body and ensures that the dirt accumulated there is sent to the lungs and kidneys for removal. There are blood vessels within the muscles of the heart to nourish itself. These veins

are divided into thin branches and provide the nutrition of the whole heart. With the calcification and hardening of this main vein of the heart, the heart cannot be fed sufficiently, this is called coronary insufficiency.

\section{Methodology:}

In the study, the first measurements (before, during, and after training) were taken one by one from the athletes at the end of the 12-week preparation period before the InterProvincial Incentive Competition in the Sakarya Boxing Provincial Representation activity program. The second measurements (before, during, and after the competition) were also made in the Inter-provincial competition held under the name of "Governorship Cup" within the activity program of Sakarya Boxing Provincial Representation. In both measurements, the values were obtained the same, before training, during training, after training, before the competition, during and after the competition.

The results obtained by comparing the same values between training and competition in the study were evaluated statistically in the SPSS 17.0 program. The competitions were held in the age categories of children, seniors, stars, youth, and adults. (http://www.vucut.org). Body temperatures were measured with an 'Omron' blood pressure device, and with a 'Comfort Model 210 DM' thermometer, primarily as blood pressure and pulse in the competitions.

\section{Results:}

Table-1: Physical Information of Boxers $(n=28)$

\begin{tabular}{llll}
\hline Parameters & Minimum & Maximum & Mean \pm SS \\
\hline Age (years) & 12 & 28 & $17.8 \pm 4.4$ \\
Body Weight $(\mathrm{kg})$ & 36 & 81 & $67.0 \pm 25.0$ \\
Height $(\mathrm{cm})$ & 145 & 178 & $166.0 \pm 19.3$ \\
\hline
\end{tabular}

Table 2: T-test Results for Training and Competition Blood Pressure (BP; mmHg) Values

\begin{tabular}{llll}
\hline Parameters & $\mathrm{n}$ & Mean \pm SS & $\mathrm{P}$ \\
\hline Pre-workout Systolic BP & 28 & $132.64 \pm 16.59$ & $0.000^{*}$ \\
Pre-competition Systolic BP & 28 & $117.64 \pm 8.33$ & \\
Pre-Competition Diastolic BP & 28 & $65.60 \pm 9.90$ & $0.001^{*}$ \\
Diastolic BP before training & 28 & $76.10 \pm 9.61$ & \\
Systolic BP during training & 28 & $135.03 \pm 13.05$ & 0.867 \\
Systolic BP during competition & 28 & $134.46 \pm 14.81$ & \\
Diastolic BP during training & 28 & $70.71 \pm 9.93$ & 0.517 \\
During the competition Diastolic BP 28 & $73.14 \pm 15.43$ & \\
Post-workout Systolic BP & 28 & $119.17 \pm 12.36$ & $0.004^{*}$ \\
Post-competition Systolic BP & 28 & $110.67 \pm 7.01$ & \\
Post-workout Diastolic BP & 28 & $68.28 \pm 11.02$ & 0.280 \\
Post-competition Diastolic BP & 28 & $65.14 \pm 10.29$ & \\
${ }^{*}$ p<o.oo1 & & & \\
\hline
\end{tabular}

Table 3: T-test results for training and competition body temperature values in $\left({ }^{\circ} \mathrm{C}\right)$

\begin{tabular}{llll}
\hline Parameters & $\mathrm{n}$ & Mean \pm SS & $\mathrm{P}$ \\
\hline Body temperature before training & 28 & $36.31 \pm 0.29$ & 0.218 \\
Body temperature before competition & 28 & $36.67 \pm 0.39$ & \\
\hline
\end{tabular}




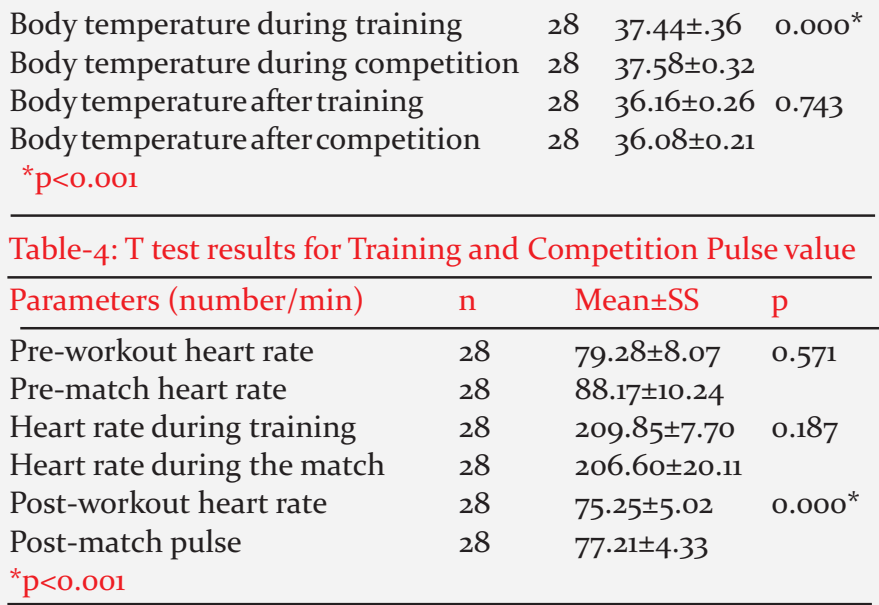

\section{Discussion and Conclusion:}

The physical parameters of our study resembles with a similar type of study where the physical parameters evaluated between handball players and boxers, the height of handball was determined as $1.72 \pm 02 \mathrm{~cm}$, while the value observed in boxers was; It was determined as $1.65 \pm 05 \mathrm{~cm}$. Again in a similar study; While some physical parameters of national and non-national taekwondo players are examined, in male national taekwondo players; their height was $1.81 \pm \mathrm{cm}$, and $1.76 \pm 5 \mathrm{~cm}$ for non-national taekwondo players. In the continuation of the study, the lengths of female national taekwondo players are; This ratio was determined as $1.72 \pm 0 \mathrm{~cm}$ and $1.64 \pm 0 \mathrm{~cm}$ in female non-national taekwondo players.

In the study conducted to find the relationship between body composition and maximal oxygen capacity in elite athletes, $175.55 \pm 1.08 \mathrm{~cm}$ in male athletes and female athletes; It was determined as $162.06 \pm 1.62 \mathrm{~cm}$. In this study, the bodyweight of the boxers was determined as $67.0 \pm 25.0$ $\mathrm{kg}$. While examining some physical and physiological parameters of top-level basketball players during the preparation period, bodyweight before the preparation period; $88.60 \pm 9.87 \mathrm{~kg}$ body weight after the preparation period; It was determined as $87.17 \pm 8.70 \mathrm{~kg}$. In this study, the mean age of the boxers was determined as $17.8 \pm 4.4$ years. In a similar study, considering the physical characteristics of basketball and handball players, the average age of handball players was determined as $12.50 \pm$ 0.60 years, while the average age of basketball players was determined as $12.86 \pm 0.83$ years.

We found a significant difference between pretraining hypertension and pre-competition hypertension, and at the same time there was a significant difference between pre-training low blood pressure and precompetition low blood pressure no significant difference was found between hypertension during training and hypertension during the competition. There was no significant difference between low blood pressure during training and low blood pressure during the competition .
Although there was a significant difference between posttraining hypertension and post-competition hypertension, there was no significant difference between post-training hypertension and post-competition hypertension.

When we examine similar studies on body temperature; It was investigated whether the effect of changing skin temperature for evaporative cooling on perspiration during exercise or not. A cycling exercise was applied to six healthy men. Esophageal temperature (Tes), skin temperature (Tsk), local skin mean temperature, lower left scapula (Tsl), local sweating rate (MSW) and skin blood flow laser Doppler flowmeter at an ambient temperature of $30-23^{\circ} \mathrm{C}(40 \% \mathrm{RH})$ Measured continuously by (LDF). Although the lower-left scapula decreased, the skin temperature remained unchanged only after the onset of sweating. It did not give the local sweating rate, but it was determined that there was a temporary and continuous increase in the early stages of exercise, and there was a positive and significant interaction between the TSL absolute value instead of the TSL change rate. Thus, evaporative cooling may be affected by local skin temperature changes in the early stages of exercise (Kondo et al., 1996).

Looking at another study, body temperature can exceed 100o W during strenuous exercise. Some of the heat produced is stored and the body center increases its temperature by a few degrees. Increases in body temperature are perceived by the center and skin heat sinks, and this sensory information is processed by the hypothalamus to elicit appropriate responses. Other sensory inputs in baroreceptors and osmoreceptors can alter these responses. The evaporation of sweat and increased skin blood flow are effective mechanisms for heat distribution throughout the body. However, dehydration impairs the capacity of sweat and body heat loss. Temperature, humid environment, or inappropriate clothing can cause heat loss in the body. Exercise training develops a tolerance to exercise by increasing the sensitivity of the relationship between sweat rate and core temperature, decreasing the initial center temperature to increase the level of sweating and total blood amount (Gleeson, 1998).

Another study was to investigate the effects of exercise on core temperature bases after exercise for blood vessel dilation and sweating. When we look at the method in this study, in 6 subjects, 3 men and 3 women, on 2 separate days, vasoconstriction decreased the mean temperature of a whole-body perfused suit until the onset of vasoconstriction. The mean body temperature was then gradually increased until vasodilation and sweating began. The study either performed a 15-minute cycle ergometry $(60 \% \mathrm{MaxVO})$ followed by 30 minutes of recovery exercise, or they sat for 45 minutes without exercise. Subjects were cooled again until the onset of skin 
vasoconstriction and followed until a rewarming period was initiated. For vasodilation and sweating, core temperature bases increased significantly after exercise at $0.49^{\circ} \mathrm{C}$ and $0.19^{\circ} \mathrm{C}$. To compare the baseline between conditions in both esophagus temperature and mean temperature changes. We mathematically compensate for changes in skin temperature using the linear skin additive established to control sweating (10\%) and vasodilation. After exercise, the onset of sweating increased from $36.79 \pm$ $0.18^{\circ} \mathrm{C}$ to $37.05 \pm 0.23^{\circ} \mathrm{C}$, to $37.11 \pm 0.21^{\circ} \mathrm{C}$ and $36.56 \pm 0.12^{\circ}$ C. . In contrast, consecutive measurements, without exercise, show a time-dependent reduction (o.18) in the onset of sweating, indistinguishable from the onset of vasodilation. These data show that exercise has an increasingly ongoing effect on temperature regulation responses after exercise (Kenny, 2000).

Looking at another study, the study aimed to directly compare the psychological results of $5 \%$ of hypohydration or ehydration both in $33^{\circ} \mathrm{C}$ environments and during $23^{\circ} \mathrm{C}$ exercise. Accordingly, 8 volunteers were taken into consideration and performed the $4 \mathrm{l}$-h exercise duration each at $60 \%$ maximum oxygen intake under the following conditions: hot-hypohydrated, hot-ohydrated, warmhypohydrated and warm euphoria. Heart rate (HR), rectal temperature, forearm blood flow, and oxygen intake were measured as a minimum of 20,40,6o exercise. Whole-body sweat rate was determined for each exercise period. Hypohydration increased more than $0.16{ }^{\circ} \mathrm{C}$ warm environment ( $0.08{ }^{\circ} \mathrm{C}$ hydration $1 \%$ ) with $1 \%$ decrease in body measurement in a hot environment. Moreover, compared to dehydration, hydration increased forearm blood flow and increased whole-body sweat during exercise in a warm rather than warm environment. Decreases in forearm blood flow and whole-body sweat rate seemed to reduce heat loss, so the increase in exercise Tre in heat while hypohydrated was calculated. This study demonstrates the psychological consequences of hypohydration during exercise that is exhausted in heat, and compared to ehydration, hydration increased forearm blood flow and increased whole-body sweat during exercise in warm rather than warm environment. It has been determined that decreases in forearm blood flow and whole-body sweat rate seem to decrease heat loss (Buono \& Wall, 200o).

In a study conducted to examine oxygen consumption and lactate profile in elite young rowers, the heart rate was determined as $179.7 \pm 12.17$ beats $/ \mathrm{min}$. When we look at the results of t-test analysis in dependent groups in this study on heart rate, no significant difference was found between the pre-training and pre-competition heart rate values $(\mathrm{p}>$ o.05), and we also saw that there was no significant difference between the heart ratevalues during training and during the competition ( $p>0.05)$. However, a significant difference was found between the post-training and post- competition heart ratevalues $(\mathrm{p}<0.05)$.

\section{Conclusions :}

It is seen that there is no significant difference between the heart rate values of the athletes before and during training, competition, but there is a significant difference between the heart rate values after training and after the competition. According to the data obtained in this study, it was determined that the training loadings applied to the athletes and the loadings under the competition conditions were important within the framework of physiological principles. Also, it is thought that the data obtained from this study will provide a data source and perspective to researchers who will study in this field.

\section{References:}

AIBA, International Boxing Association. (2010). Technical \& Competition Rules. 2010.

Astrand, P. \& Rodahl, K. (1986): Textbook of work physiology. New York, United States.

Beneke, R., Beyer, T., Jachner, C., Erasmus, J. \& Hutler, M. (2004): Energetics of karate kumite. Eu. J. Appl. Physiol., 92(4-5):518523.

Buono, M.J. \& Wall, A.J. (200o): Effect of hypohydration on core temperature during exercise in temperate and hot environments. Pflugers Arch., 440(3):476-48o.

Chatterjee, P., Banerjee, A.K., Majumdar, P. \& Chatterjee, P. (2006): Changes in Physiological Profile of Indian Women Boxers During a Six Week Training Camp. Int. J. Appl. Sports Sci.,18(2):39-49.

El-Ashker, S. (2011): Technical and tactical aspects that differentiate winning and losing performances in boxing. Int. J. Perform. Anal. Sport, 11(2):356-364.

Ghosh, A.K. (2010): Heart rate, oxygen consumption and blood lactate responses during specific training in amateur boxing. Int. J.Appl. Sports Sci., 22(1):1-12.

Ghosh, A.K., Goswami, A. \& Ahuja, A. (1995): Heart rate \& blood lactate response in amateur competitive boxing. In. J. Med. Res., 102:179-183.

Ghosh, A.K., Goswami, A., Mazumdar, P. \& Mathur, D.N. (1991): Heart rate \& blood lactate response in fieldhockey players. Int.J.Med. Res., 94:351-356.

Gleeson, M. (1998): Temperature regulation during exercise, School of Sport and xercise Sciences, University of Birmingham, Edgbaston, England. Int. J. Sports Med., 19(2):96-99.

Gleeson, M. (2002): Biochemical and immunological markers of overtraining. L. Sports Sci. Med., 1(2):31-41.Kenny,

Khanna, G.L. \& Manna, I. (2006): Study of physiological profile of Indian boxers. J. Sports Sci. Med., 5 (CSSI):90-98.

Kenny, G.P., Proulx, C.E., Denis, P.M. \& Giesbrecht, G.G. (200o): Moderate exercise increases he post exercise resting warm thermoregulatory response thresholds. Aviat. Space Environ. Med., 71(9):914-915.

Kondo, N., Nishiyasu, T. \& Ikegami, H. (1996): The influence of exercise intensity on sweating efficiency of the whole body in a mild thermal condition. Fac. Hum. Develop., Kobe Uni., 39(2):225-231. 


\section{ORIGINAL ARTICLE}

Kraemer, W.J., Fleck, S.J. \& Deschenes, M.R. (2011): Exercise physiology: integrating theory and application. Pub. by: Philadelphia, United States:

Lippincott Williams \& Wilkins.Kravitz, L., Greene, L., Burkett, Z. \& Wongsathikun, J. (2003): Cardiovascular response to punching tempo. J. Streng. Cond. Res., 17(1):104-108.

Toskovic, N.N., Blessing, D. \& Williford, H.N. (2002): The effect of experience and gender on cardiovascular and metabolic responses with dynamic Tae Kwon Do exercise. J. Streng. Condit. Res.,16(2):278-285.

Umeda, T., Suzukawa, K., Takahashi, I., Yamamoto, Y., Tanabe, M. \& Kojima, A. (2008): Effects of intense exercise on the physiological and mental condition of female university judoists during a training camp. J. Sports Sci., 26(9):897-904.
Ambient Science, 2020: Vol. 07(Sp1); 288-292 DOI:10.21276/ambi.2020.07.sp1.oa41

Urhausen, A. \& Kindermann, W. (2002): Diagnosis of overtraining: what tools do we have? Sports Med., 32(2):95102.

Warburton, D.E., Welsh, R.C., Haykowsky, M.J., Taylor, D.A. \& Humen, D.P. (2002): Biochemical changes as a result of prolonged strenuous exercise. Br. J. Sports Med., 36(4):301303.

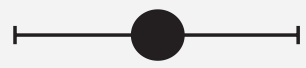

